This item was submitted to Loughborough's Research Repository by the author.

Items in Figshare are protected by copyright, with all rights reserved, unless otherwise indicated.

\title{
Reducing in-cylinder parasitic losses through surface modification and coating
}

PLEASE CITE THE PUBLISHED VERSION

http://dx.doi.org/10.1177/0954407013512626

PUBLISHER

(C) IMechE

VERSION

AM (Accepted Manuscript)

\section{PUBLISHER STATEMENT}

This work is made available according to the conditions of the Creative Commons Attribution-NonCommercialNoDerivatives 4.0 International (CC BY-NC-ND 4.0) licence. Full details of this licence are available at: https://creativecommons.org/licenses/by-nc-nd/4.0/

\section{LICENCE}

CC BY-NC-ND 4.0

\section{REPOSITORY RECORD}

Howell-Smith, S.J., Homer Rahnejat, Paul King, and D. Dowson. 2014. "Reducing In-cylinder Parasitic Losses Through Surface Modification and Coating”. Loughborough University. https://hdl.handle.net/2134/25726. 
Reducing in-cylinder parasitic losses through surface modification and coating

Sebastian Howell-Smith ${ }^{1}$, Homer Rahnejat² ${ }^{2}$ Paul D King ${ }^{2}$ and

Duncan Dowson 2,3

\section{Abstract}

Friction constitutes nearly one fifth of all engine losses. The main contributory source of frictional losses in most engines is the piston-cylinder system, accounting for nearly half of all the parasitic losses. Minimisation of this is essential for improved fuel efficiency and reduced emissions, which are the main driving forces in engine development. The tribology of piston-cylinder conjunctions is, however, transient in nature. This means that various palliative actions need to be undertaken to suit certain instances during the engine cycle. In general, formation of a coherent film of lubricant of suitable viscosity reduces the chance of boundary interactions for most of the piston cycle. Plateau honing of the cylinder bore surface reduces the 'peakiness' of the surface topography. Furthermore, if regularly spaced grooves are provided on the contacting surface, these grooves can act as reservoirs of lubricant. However, at low sliding speeds, which are typically found during piston motion reversals, lubricant entrainment into the contact either ceases or is significantly reduced. Therefore, at the end of the piston strokes, there is a greater chance of boundary interactions, resulting in increased friction. There is a need to engineer the surface topography in these low-relative-speed regions in a manner conducive to the retention of a lubricant film. Surface texturing by means of laser processing or mechanical indentation at the dead centres are used to produce local reservoirs of lubricant as well as to encourage and direct the flow of lubricant into the contact conjunction. The paper shows that such surface-modifying features improve the engine's output power by as much as $4 \%$ over that of the standard cylinder bore surface. To reduce wear and scuffing, particularly at the top dead centre, hard coatings can also be used. However, smooth surfaces and the generally oleophobic nature of hard coatings can increase the chance of adhesion, particularly at low sliding speeds. This means that prevention of wear does not necessarily lead to improved fuel efficiency. Furthermore, it is necessary to determine the geometry of the textured patterns in order to avoid the leakage of oil from the ring-pack conjunctions, which can result in increased emissions as well as lubricant degradation and depletion.

\section{Keywords}

Piston-cylinder system, friction, parasitic losses of the engine, laser surface texturing, hard wear-resistant coatings

\section{Introduction}

The fuel efficiency and the exhaust emissions are the key driving forces in modern internal-combustion (IC) engine development. The former is tackled by various palliative measures within a multi-disciplinary approach. These include reductions in 
the mass and the inertia, where possible, without affecting the structural integrity and the noise and vibration refinement. ${ }^{1}$ In addition, reductions in the thermal and parasitic losses are key development targets. While thermal losses account for 50 $60 \%$ of the fuel energy in modern IC engines, the parasitic losses, consisting of friction and

pumping, account for a further $15-20 \%$, according to Andersson. ${ }^{2}$ The main source of frictional losses ( $45 \%$ of all such losses) is attributed to the piston-cylinder subsystem. Thus, the piston skirt and ring-pack conjunctions with the cylinder liner account for $6-9 \%$ of the fuel energy consumed. Therefore, significant gains in the fuel efficiency and the output power may be accrued by reducing these losses. This paper focuses on the frictional losses of the piston system.

For the piston system conjunctions, the regime of lubrication is transient because of large variations in the contact kinematics and the applied loads throughout the engine cycle. ${ }^{3}$. As a consequence, the thickness of the lubricating film formed between the piston rings, as well as between the piston skirt and the cylinder liner, varies during the engine cycle. Thin films formed at piston reversals can lead to direct surface interactions, promoting additional boundary friction to the usual viscous friction. To reduce the viscous friction, lower-viscosity lubricants may be used. However, this can lead to a reduced load-carrying capacity in other more loadintensive engine conjunctions such as the cam-tappet contact. Hence, the trend in the formulation of lubricants has been mixing of boundary lubricants and additives in a blend of high-viscosity and low-viscosity base oils. ${ }^{4}$ Boundary interactions cannot be avoided altogether, because of cessation of the lubricant entraining motion at the top dead centre (TDC) and the bottom dead centre (BDC), where the piston motion undergoes reversal, i.e. momentary cessation of the sliding motion (e.g. at the TDC and the BDC). In these locations, only a thin film of lubricant through squeeze-film action and entrapment within the surface topography is possible.

Although interactions of the surface asperities in dry contacts underlies the very definition of friction, ${ }^{5,6}$ their very existence can also be useful in mitigating the same for wet surfaces. In fact, progressively tribology of real rough surfaces is regarded as a lubricant-surface system. ${ }^{7}$ The near-surface action of additives in boundary lubricants is just one example of this systematic view of tribology. ${ }^{8}$ It has long been established that rough surfaces, through retention of a lubricant film, can reduce friction when a coherent film of lubricant of sufficient thickness cannot be assured. In fact, the entire working surfaces of cylinder bores are typically cross-hatched uniformly by means of the honing process, creating shallow grooves which may act as reservoirs of lubricant. These pockets of lubricant have been shown to encourage the microwedge effect in a relative sliding motion of the surfaces. ${ }^{9,10}$

In the case of cross-hatch honing, the effect of the honing angle relative to the direction of sliding has been investigated through numerical analysis by Michail and Barber $^{11}$ and Spencer et al. ${ }^{12}$ In recent years, a host of other surface treatment techniques have emerged, including laser surface texturing (see, for example, the 
papers by Ryk et al., ${ }^{13}$ Kovalchenko et al., ${ }^{14}$ Rahnejat et al. ${ }^{15}$ and Etsion and Sher ${ }^{16}$ ), lithographic techniques and various

mechanical techniques such as engraving, indentation, embossing and vibro-rolling. Dumitru et al. ${ }^{17}$ and Andersson et al. ${ }^{18}$ have provided comprehensive reviews of the various techniques. Kovalchenko et al. ${ }^{14}$ reported a series of lubricated sliding experiments with different surfaces, consisting of rough ground, very smooth and dimpled surfaces. They showed consistently lower coefficients of friction for laseretched surfaces with conical dimples at lower sliding speeds. At higher sliding speeds, the beneficial effect of dimpling was lost, which was also shown by Morris et al. ${ }^{19}$ for the case of a pad journal bearing. In fact, Morris et al. ${ }^{19}$ demonstrated that, under fully developed hydrodynamic conditions, surface modifications can lead to increased side leakage from the conjunction.

Etsion ${ }^{20}$ provided a review of the latest developments in laser surface texturing and reported retention of the lubricant within dimpled, although otherwise parched surfaces, reducing friction by as much as $2-4 \%$. Rahnejat et al. ${ }^{15}$ also reported a similar decrease in friction through the use of laser-ablated patterned features on the surface of the advanced coated cylinder liners in the TDC region, which are used for motor racing applications. A comprehensive analysis of various surface texture features has been given by Rahmani et al. ${ }^{21}$ Increasingly, high-performance engines and components are constructed from light alloy materials. This can drastically reduce the inertial forces developed. In the case of the cylinder bore surface, aluminium and its alloys typically perform poorly compared with the more traditional, although far heavier centrifugally cast iron (whether as individual liners or integrally cast within the block structure). This is due to the relatively poor wear and scuff performance of aluminium surfaces.

This situation can be improved with the addition of hard wear-resistant coatings applied by various processes such as electroplating or chemical vapour deposition (CVD). ${ }^{22-24}$ In recent years, thin plasma-assisted CVD 'diamond-like carbon (DLC) coatings' have also been tried. ${ }^{25}$ Mistry ${ }^{26}$ investigated the frictional performances of DLC coatings with a range of lubricants. He noted that, with an optimum choice of lubricant, the coefficient of friction was reduced by nearly $30 \%$ relative to an uncoated steel substrate. This surface treatment has not hitherto found use outside the laboratory environment for cylinder bore surfaces.

With a suitable bore material and/or surface coating in place, the working surfaces can then be locally textured by means of laser ablation or indentation in addition to the overall roughness generated by the aforementioned cross-hatch honing. This suggests that a significant reduction in friction may be achieved with surfacemodified coated liners.

There is a dearth of testing and measurement with regard to suitable coatings and texturing work for cylinder liners. This paper is an attempt to reduce the prevailing knowledge gap. 


\section{Experimental set-up}

To ascertain the influence of various piston and cylinder coatings and/or textured surfaces, it is important to conduct repeatable and controlled tests under realistic and representative conditions. This means that fired engine tests under a range of normal operating conditions, which are representative of a large range of engine speeds, should be undertaken. In tribological terms a host of regimes of lubrication are experienced in the piston-cylinder system, governed by the speed-load combination. High-performance engines such as race engines are subject to piston sliding speeds ranging from $0 \mathrm{~m} / \mathrm{s}$ to over $40 \mathrm{~m} / \mathrm{s}$ and to contact loads in excess of 5 $\mathrm{kN}$. This range of speed-load conditions encompass most tribological conditions; thus the results would be pertinent to many engine types, including those used in normal road vehicles. Note that the sliding speed is the most important parameter in the mechanism of film formation and, for most original equipment manufacturer (OEM) engines, the sliding speed throughout the piston cycle remains within the testing range of the high-performance engine used here.

It is necessary to test a range of coatings and surface-textured liners and piston skirts, as well as carrying out a significant number of tests at different engine speeds. Use of a single-cylinder engine would reduce the otherwise inordinate cost of the manufacture of parts, the in-cylinder instrumentation and the large number of required tests. However, the proportion of parasitic losses in a single-cylinder engine is often different from that in multiple-cylinder engines, with losses by engine bearings accounting for a larger portion of the overall losses than in multiple-cylinder engines. ${ }^{27}$ Therefore, with single-cylinder engines, any small predicted gains of a few percentage points as the result of coatings or surface texturing may be difficult to determine accurately by the usual indirect measurement through any gain in the brake mean effective power. However, several high-performance single-cylinder motocross engines employ rolling element bearings instead of journal bearings for the crankshaft mains and big-end (connecting-rod) bearing. This considerably reduces the bearing losses, making the piston-cylinder system the main source of parasitic losses.

Adequately preloaded or interference-fitted rolling element bearings operate in the elastohydrodynamic regime of lubrication, where rolling contact friction is quite insignificant (coefficient of friction in the range 0.005-0.01).4 Therefore, the proportion of frictional losses due to the piston-cylinder system would be well in excess of that for an OEM engine, as noted in the work by Andersson. ${ }^{2}$

Nevertheless, the use of rolling element bearings in single-cylinder engines results in further deviation from conditions that would be expected from multi-cylinder OEM variants.

For testing, a Honda CRF-450R motocross engine was chosen because of its high rotational speed capability. ${ }^{28}$ This engine is capable of maximum piston speeds in excess of $40 \mathrm{~m} / \mathrm{s}$, thereby enveloping the full range of engine speeds, except for a few limited cases. The basic details for this engine are provided in Table 1. 
The Honda CRF-450R engine, as supplied, features a cast aluminium cylinder block. The cylinder block is coated on the bore surface with electrolytically applied nickel and a co-deposited silicon carbide particulate ( $\mathrm{Ni}-\mathrm{SiC})$. This configuration needed to be altered to enable rapid introduction of cylinder liner variants with different coatings and/or modified surface topography. A redesigned cylinder block (wet liner arrangement) is used to accommodate various interchangeable liner types.

Table 1. Engine characteristics of the Honda CRF-450R. ${ }^{27}$

\begin{tabular}{ll} 
Engine type & $\begin{array}{l}\text { Water-cooled four-stroke four-valve } \\
\text { single-cylinder, normally aspirated } \\
\text { Gasoline }\end{array}$ \\
$\begin{array}{l}\text { Fuel } \\
\text { Engine displacement }\end{array}$ & $449 \mathrm{~cm}^{3}$ \\
Bore & $96 \mathrm{~mm}$ \\
Stroke & $62.1 \mathrm{~mm}$ \\
Compression ratio & $11.5: 1$ \\
$\begin{array}{l}\text { Maximum quoted power (specific } \\
\text { power) }\end{array}$ & $41 \mathrm{~kW}$ at $9000 \mathrm{r} / \mathrm{min}(91.31 \mathrm{~kW} / \mathrm{dm} 3)$ \\
$\begin{array}{l}\text { Maximum quoted torque (specific } \\
\text { torque) }\end{array}$ & $49.8 \mathrm{~N} \mathrm{~m}$ at $7000 \mathrm{r} / \mathrm{min}(99.80 \mathrm{~N}$ \\
\hline
\end{tabular}

\section{Engine test bed}

The modified Honda CRF-450R engine was mounted on a test bed and coupled via its gearbox drive sprocket to a $250 \mathrm{~kW}$ Ricardo S3000/3345 Taskmaster transient a.c. dynamometer, capable of braking at a maximum speed of $11,000 \mathrm{r} / \mathrm{min}$. The test cell featured a controlled environment, which was maintained through measurement of the temperature, pressure and humidity, using an Airflow DB2 digital barometer. The dynamometer control provided the output power as well as the engine torque. An encoder with 3600 pulses/ rev was used to measure the engine speed accurately.

The encoder also provided a 'TDC' pulse, triggering incylinder pressure data acquisition by a Kistler pressure sensor incorporated within a replacement spark plug.

The water jacket temperature, the exhaust gas temperature and the air-to-fuel ratio with respect to the stoichiometric air-to-fuel ratio were also monitored. The air-to-fuel ratio for the modified Honda CRF-450R engine was found to be in the range between 12.5 and 13.2 for the wide-open throttle condition. The water jacket temperature was kept at $120^{\circ} \mathrm{C}$ for all the tests carried out. These precautions were taken in order to ensure that the variation in combustion remained below $1 \%$ for any given engine speed. 
Various cylinder liner configurations Replaceable Honda CRF-450R wet cylinder liners were made from different substrate materials. Three alternative liner types were used in this investigation.

The first type was made from the aluminium-silicon alloy AA4032, because of its similar composition to the standard OEM barrel. This liner is referred to as L2017-C and is regarded as the baseline liner, with respect to which the performances of all the other liner variants were measured (Table 2). This and all the other liner derivatives with the exception of the cast iron version were $\mathrm{Ni}-\mathrm{SiC}$ electrolytically plated, thereby producing a cylinder surface with far improved tribological performances compared with that of the base aluminium alloy. After electroplating, all parts including cast iron, which is more representative of OEM cylinders, were cross-hatch honed (Figure 1(a)), resulting in a nominal plating thickness of $75 \mathrm{~mm}$ (Figure 1(c)). The resulting surface (Figure 1(b)) features linearly spaced overlapping grooves worn into the surface owing to the third-body action of abrasive media. Under loaded contact, these grooves in the surface topography are expected to act as lubricant reservoirs which encourage the microwedge effect, entraining a film of lubricant into the contact regions. This has been demonstrated to be the case numerically by Michail and Barber ${ }^{11}$ and Spencer et al. ${ }^{12}$ Figure 1 (b) shows an image of a honed surface using the Zygo Newview 5000 white-light interferometer with a resolution of $1 \mathrm{~nm}$. The corresponding two-dimensional surface roughness of this type of liner is $R a=0.2-0.3 \mu \mathrm{m}$. The mean surface roughness $\mathrm{Ra}$, however, provides inadequate surface characterisation; ${ }^{28}$ additional parameters usually specified include the proportion of peaks protruding above the average plateau height $\mathrm{Mr}_{2}$, the peak surface roughness $R_{p k}$, the average plateau height $R_{k}$ and the valley surface roughness $R_{v k}$, in addition to the cross-hatch angle discussed earlier. In addition, a small amount of plateau finish is introduced by means of a finishing operation which effectively removes the highest asperity peaks. This removal of peaks also occurs during the initial running-in wear. These processes ensure that the resulting topographical features do not conform to a Gaussian distribution. A combination of the skewness of distribution for topographical features and kurtosis is further used to characterise the honed cylinder liner surfaces (see Appendix 2). The usual surface roughness parameters for all the liners are given in Table 3 . These values, together with the parameters in Appendix 2 fully describe the surface topography of the various liner variants. 
Table 2. Various cylinder liners with a coating and surface treatment at the TDC.

\begin{tabular}{|c|c|c|c|c|}
\hline Liner reference & Base material & Surface coating & $\begin{array}{l}\text { Surface } \\
\text { finish } \\
\text { (Table 3) }\end{array}$ & $\begin{array}{l}\text { TDC additional } \\
\text { treatment }\end{array}$ \\
\hline L2017-A & AA2618 aluminium alloy & $\begin{array}{l}\text { Electroplated nickel-silicon carbide } \\
(50-80 \mu \mathrm{m} \text { thick })\end{array}$ & Type I & None \\
\hline L2017-B & AA4032 aluminium alloy & $\begin{array}{l}\text { Electroplated nickel-silicon carbide } \\
(50-80 \mu \mathrm{m} \text { thick }) \\
\text { overlaid with } \mathrm{I}-3 \mu \mathrm{m} \text { of diamond-like } \\
\text { carbon }\end{array}$ & Type 2 & None \\
\hline L2017-C & AA4032 aluminium alloy & $\begin{array}{l}\text { Electroplated nickel-silicon carbide } \\
(50-80 \mu \mathrm{m} \text { thick) }\end{array}$ & Type I & None \\
\hline L2017-G & Meehanite 350 cast iron & None & Type 3 & None \\
\hline L2017-L & AA4032 aluminium alloy & $\begin{array}{l}\text { Electroplated nickel-silicon carbide } \\
(50-80 \mu \mathrm{m} \text { thick })\end{array}$ & Type I & TDC laser etched \\
\hline L20I7-M & AA4032 aluminium alloy & $\begin{array}{l}\text { Electroplated nickel-silicon carbide } \\
(50-80 \mu \mathrm{m} \text { thick })\end{array}$ & Type I & TDC pyramid indented \\
\hline
\end{tabular}

TDC: top dead centre.

Table 3 also shows that the cross-hatch angle in the range $30-40^{\circ}$ is ensured for all the liner variants, this being the optimal angle found through parametric numerical analysis by Michail and Barber ${ }^{11}$ and Spencer et al. ${ }^{12}$ The second type of liner was made of aluminium alloy AA2618, which is an alloy possessing high mechanical properties at elevated temperatures. As such, this alloy is commonly specified for high-output-power race-type applications. This liner (L2017-A) was also coated with nickel-based electrolytic coating and had the same roughness characteristics after honing. The third liner variant is uncoated cast iron (L2017-G), which is plateau honed to anominal Ra value of $0.3-0.4 \mu \mathrm{m}$. Cast iron is investigated, because it is the traditional material for cylinder liners in OEM engines and, therefore, allows a logical comparison with the more modern lightweight materials and bore coatings. It should be noted that, in the cold running condition, all parts were of nominally the same internal diameter. As cast iron undergoes less thermal expansion than aluminium does, a thinner conjunction results when the engine is running at operating temperatures. A difference between thermal expansion tribological conditions in OEM engines and the high-performance tests carried out here is the use of cast iron liner inserts for the former. This indicates that thinner films would be expected in some OEM engines, using cast iron and lower sliding speeds. 

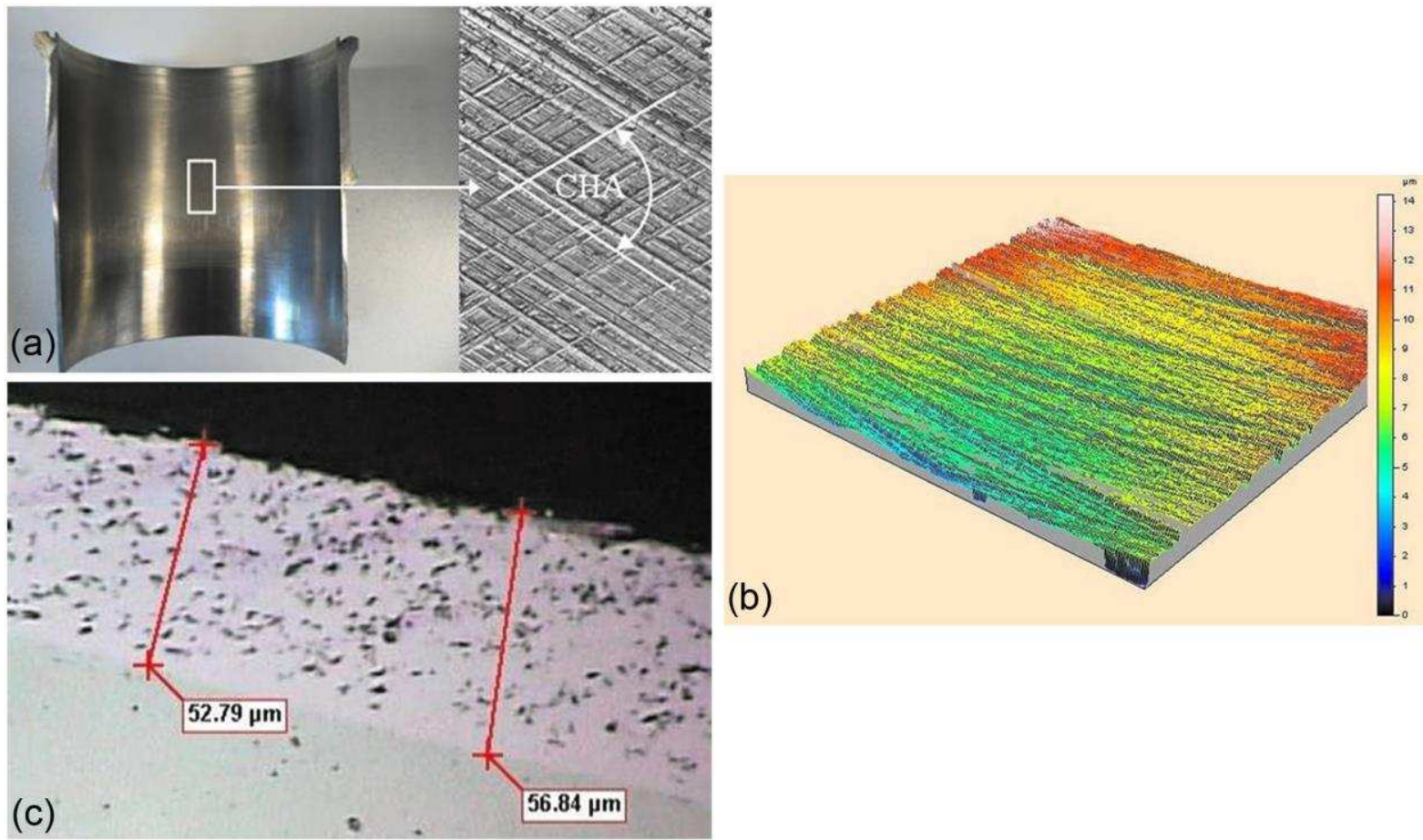

Figure 1. Surface treatments for various cylinder liners: (a) cross-hatch honed bore surface, showing the resulting cross-hatch angle; (b) an interferometric image of a honed cylinder bore surface; (c) cross-section through an electrolytically applied $\mathrm{Ni}-\mathrm{SiC}$ bore coating.

CHA: cross-hatch angle.

Table 3. Surface roughness parameters for various surface types.

\begin{tabular}{lccc}
\hline Surface parameter & \multicolumn{2}{l}{ Value for the following surface types } \\
\cline { 2 - 4 } & Type I (standard) $(\mu \mathrm{m})$ & Type 2 (smooth) $(\mu \mathrm{m})$ & Type 3 (plateau) $(\mu \mathrm{m})$ \\
\hline$R_{a}$ & $0.2-0.3$ & $0.06-0.08$ & $0.3-0.4$ \\
$R_{k}$ & $0.4-1.0$ & $0.05-0.3$ & $0.2-0.6$ \\
$R_{p k}$ & $>0.3$ & $<0.2$ & $<0.2$ \\
$R_{v k}$ & $>0.3$ & $>0.08$ & $1.0-2.5$ \\
$R_{z}$ & $0.9-2.60$ & $0.25-0.65$ & $3.0-7.0$ \\
Cross-hatch angle (from the horizontal) & $30-40^{\circ}$ & $30-40^{\circ}$ & $30-40^{\circ}$ \\
\hline
\end{tabular}

In addition to the above, some liners are furnished with a thin coating of DLC, utilising L2017-A as the base part (Table 2). For deposition of DLC a much smoother base surface finish is required $(\mathrm{Ra}=0.04-0.06 \mu \mathrm{m})$. This was achieved with an additional honing operation. The DLC coating (typical thickness, $2 \mu \mathrm{m}$ ) was applied using plasma-assisted CVD of carbon- and hydrogen-rich feed gases. This resulted in a $70 \% \mathrm{sp}^{3}$ (diamond) structure, with a hardness of 10-40 GPa. This part is identified as L2017-B in Table 2.

\section{Engine test results}

A series of tests was carried out for all the liner configurations (see the section on various cylinder liner configurations) for a range of engine speeds with wideopen throttle. The Honda CRF-450R engine used in this analysis is primarily used for motocross motorbike races, where it is driven with wide-open throttle for 
nearly $90 \%$ of a race with intermittent closed throttle.

The testing conditions reported here strive to replicate the race conditions. Furthermore, the engine idling condition is at $4000 \mathrm{r} / \mathrm{min}$; thus, speeds below 5000 $\mathrm{r} / \mathrm{min}$ have no practical meaning. In all cases the same nominal piston type, ringpack and lubricant (SAE grade 10W40, ACEA A3/B4) were used. All cylinder liner variants were tested on the modified Honda CRF-450R single-cylinder engine (Figure 1). The liner performance is gauged against the baseline liner L2017-C described in the section on various cylinder liner configurations (Table 2).

The test procedure is provided in Appendix 3. There are potentially many variants which can affect the comparative nature of the results. These variations should be kept to a minimum, thus requiring a strict procedure to ensure repeatable operating conditions. In particular, all liner variants were measured on a coordinate measuring machine (CMM) at various cross-sections and along the cylinder's axial direction to ensure close dimensional similarity. The measurements showed that $97 \%$ of all liners conform to the same nominal diameter. The CMM measurement repeatability is $61.5 \mathrm{~mm}$ over the nominal cylinder diameter. More than 2000 diameters were measured for any given cylinder.

Another source of error is the manufacturing variability of the ring pack and piston skirt, as well as their wear in any sequential series of tests. Therefore, the same piston and ring pack was used for all these tests.

This combination was subjected to a period of running in (Appendix 3 ) in order to make sure that the periods of initial and gradual wear had elapsed and that their surfaces may be considered as fully embedded. This procedure and the appropriate surface topographical parameters indicating the state of wear have been described by Gore et al. ${ }^{29}$ The embedded ring pack and piston were used in all the tests with the various liner types. Therefore, any topographical and geometrical variability emanating from the use of different pistons and ring packs was eliminated. In cases where a new set consisting of a piston and a ring pack was required, because of their failure, the same procedure was repeated. The compression ring tension is another source of variability which should be guarded against, even with the use of the same ring throughout testing.

It should be noted that the nitride steel compression ring used throughout the tests is far less susceptible to variation in the ring tension than are the traditional heatformed ductile iron rings. Although ring tension plays an important role, the contact force is mainly affected by the combustion pressure acting behind the compression ring rim. Theaker et al. ${ }^{30}$ showed that, for the Honda CRF-450R compression ring combustion, pressure loading accounts for nearly $90 \%$ of the instantaneous contact load.

The output torque at a given load site was measured in each case by the transient dynamometer and converted into power. This measured power was corrected for atmospheric conditions in accordance with the SAE J1349 JUN90 standard. The 
result for each liner's corrected output power was divided by the corresponding value obtained for the baseline liner in order to obtain a percentage power loss or gain as

\section{Percentage power differential}

$=\frac{P_{\text {linervariant }}}{P_{\text {baseline }}} \times 100$ at a given engine speed $(r / \mathrm{min})$

he average gains of a series of tests in the same conditions are plotted in Figure 2.

The percentage gain in power is relative to the baseline cylinder liner configuration in each test series.

They do not represent any potential reduction in friction in an OEM engine, where a lower proportion of

frictional losses is attributed to the piston-cylinder system, as noted by Andersson.2 It is important to note that the piston-cylinder proportion of frictional losses in the Honda CRF-450R engine is much higher than in multiple-cylinder OEM engines because of the use of rolling element bearings for the connecting rod and main crankshaft support.

Results of coated and honed liners Figure 2 shows that the cast iron liner performs consistently worse than the baseline liner does, while the opposite is generally true for the Ni-SiC-coated aluminium alloy AA2618 variant. Typically, aluminium and its alloys have far higher thermal conductivities and undergo more thermal expansion than do ferrous materials, including cast iron. Therefore, one conclusion that can be drawn from this result is that the generated conjunctional heat is conducted through the cylinder wall more readily in the aluminium case, hence reducing the temperature of the fluid film on the cylinder surface.

Furthermore, because of the increased thermal expansion in the case of aluminium alloys, the average conjunctional clearance increases. In combination, these phenomena result in a thicker higher-viscosity film between the piston and cylinder liner wall. Generally, thicker higher-viscosity films have increased load carrying capacity and result in a reduced likelihood of asperity interactions. OEM engines, mostly using cast iron liner inserts, would undergo less thermal expansion since they are additionally constrained by the solid surface of the bore. Thinner lubricant films, and thus higher friction at the same sliding speed, would be expected for these engines relative to the racing variants. However, the conclusions with regard to the cast iron liner should be given in detail because, in many OEM applications, different piston material (steel) and skirt profiles are usually employed to guard against the thermal expansion mismatch which in this study was surmised to occur between an aluminium piston and a cast iron liner. In motorsport applications, use of a lightweight piston is seen as essential because of the reduced inertial imbalance at high piston speeds. The same is not true of many OEM engines. As noted, conjunctional heat generation is a function of the materials of the boundary solids and the running clearance which directly affects friction. It is clearly possible to 
design for larger running and cooler clearances, which can reduce friction, but may lead to a poorer noise, vibration and harshness performance.

Surface interactions still take place in the piston skirt-cylinder bore and ring-packcylinder bore conjunctions. As described above, these typically occur during cold start-up conditions and at piston reversals at the TDC and the BDC, as measured directly by Furuhama and Sasaki ${ }^{31}$ and Gore et al. ${ }^{32}$ For much of the expansion (power) stroke, particularly at high combustion pressures and during reversals, mixed or boundary regimes of lubrication would be expected. . $^{311}$, 33-35

It is also often the case that a coherent meniscus is not maintained to supply the conjunction. Therefore, to limit the component wear, hard wear-resistant coatings are often used. In preparation for hard surface coatings, smoother substrate surfaces are often required. Smoother surfaces generally assist the required cleaning processes and prevent the cracking of hard coatings due to residual stresses. Hard coatings (with a higher modulus than that of the substrate material) retain the subsurface stress field within the coating layer itself, thereby protecting the substrate from any inward crack propagation. ${ }^{36-38}$ Therefore, the thickness of the coating layer should ideally be optimised through contact mechanics analysis. This is in order to ensure that the maximum subsurface stresses do not exceed the adhesion strength of the coating or coincide with the coating-substrate interface, thus leading to its exfoliation ${ }^{39}$ or causing inelastic deformation of the coating. ${ }^{40,41}$

There are also limitations with regard to the choice of coating technology, such as physical vapour deposition, CVD or electroplating technique. Manufacturing and fabrication costs and output volume also play an important role in opting for a certain coating thickness.

For instance, for a DLC coating a thickness of 2-4 mm is often used for highly loaded contacts. A major drawback with high-elastic-modulus coatings is the greatly reduced tendency to deform locally within the conjunction, thus minimising the chance of elastohydrodynamic lubrication. Nevertheless, for the piston skirt, the global (bulk) thermoelastic deformation accounts for the main gap-generating mechanism. ${ }^{42,43}$ Apart from the Ni-SiC coated baseline and aluminium alloy AA2618 liners, a DLC-coated liner with a smoother surface finish of $\mathrm{Ra}=0.04-0.06 \mathrm{~mm}$ (L2017-B) was also tested (Figure 3). This DLC-coated liner with a much smoother surface produces an inferior power to that of the baseline liner for lower engine speeds, irrespective of its enhanced surface finish. The performances of the two liners merge at higher engine speeds. Smoother surfaces reduce the chance of lubricant retention between the shallow valleys of their topographies. Because of the fine surface finish prior to DLC coating, and the non-levelling nature of the coating, the part still retains a very fine cross-hatch. These shallow grooves therefore have a relatively low lubricant retention capacity. DLC deposition limitations require the use of very fine finishes which result in a high deposited hardness, effectively preventing any opportunity of post-process honing. The shallow nature of the grooves is particularly important at or close to the stroke reversals. 
However, the DLC coating reduces the chance of wear and subsequent scuffing, which is often noted at the TDC.

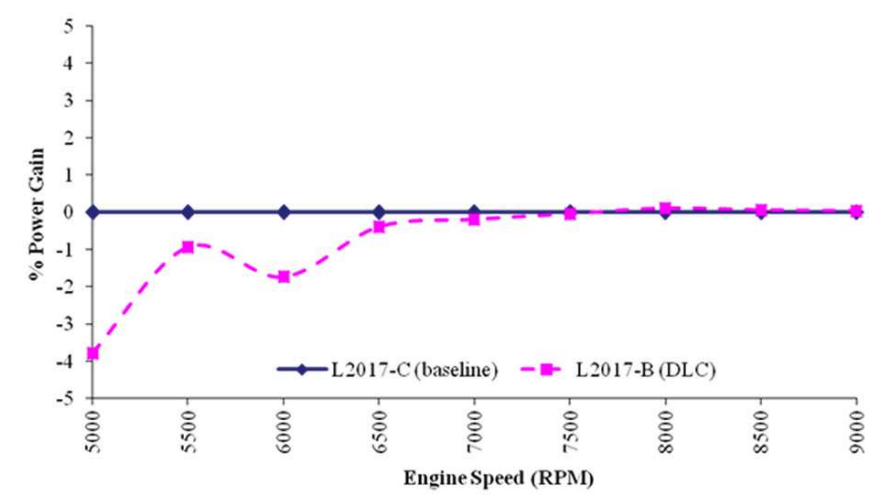

Figure 3. Performance of the DLC-coated liner relative to the baseline liner.

RPM: r/min.

\section{Results of textured surfaces}

The results obtained thus far are consistent with the expectation that some degree of surface roughening would introduce lubricant reservoirs, leading to the microwedge effect. 13, 15, 20 To investigate this, a series of liners were textured and benchmarked against the baseline liner performance. Other researchers have already shown improvements in friction reduction by partial texturing of the flat contacting land of a chamfered piston compression ring with dimples. ${ }^{16,20,44,45}$ This represented an option for the current study.

However, numerical analysis concerning the current engine showed that, for the hexanomial ring crown profile (with no flat contacting land) used in the Honda CRF450R engine, the regime of lubrication is mixed only in the reversal in transition from the compression to the power stroke and within the latter prior to the point of maximum combustion. ${ }^{46}$ The lubricant flow through the ring is sufficient for the fully flooded condition elsewhere. ${ }^{46}$ Thus, any additional microwedge effect was surmised to lead to loss of sealing. Therefore, surface textures were provided on the cylinder liner in this investigation. Numerical analysis of the piston skirt-cylinder liner contact by Balakrishnan et al. ${ }^{10}$ showed pressure spikes at the leading edge and trailing edge of the contact because of the discontinuities in the skirt's axial profile at these positions (see the isobaric pressure plot in Figure 4). When Balakrishnan et al. superimposed the predicted lubricant flow pattern upon the isobaric pressure plot, it became clear that the pressure spike at the inlet to the contact inhibits the flow of lubricant into the contact zone. Most of the flow took place on the shoulders of the contacting region (the inset to Figure 4). The results in Figure 4 correspond to the piston contact with the baseline liner in the engine tests. Using the laser-textured pattern shown in Figure 5(a) at the TDC region, Rahnejat et al. ${ }^{15}$ reported an output torque gain of $2-4 \%$. This pattern consists of a primary horizontal track of alternating semicircular crescents (the middle row in the figure). The crescents are typically 0.5 
$\mathrm{mm}$ high and $2 \mathrm{~mm}$ long, situated such that they align with the compression ring when the piston is at the TDC position. Additional rows of horizontal tracks appear above and below the primary track with $0.25 \mathrm{~mm}$ spacing. Figure $5(\mathrm{~b})$ shows new numerical predictions, using the same analysis method as in the paper by

Balakrishnan et al., ${ }^{10}$ indicating significant inward flow into the high-pressure contact inlet region due to lubricant entrainment, induced by the laseretched features which facilitate the microwedge effect.

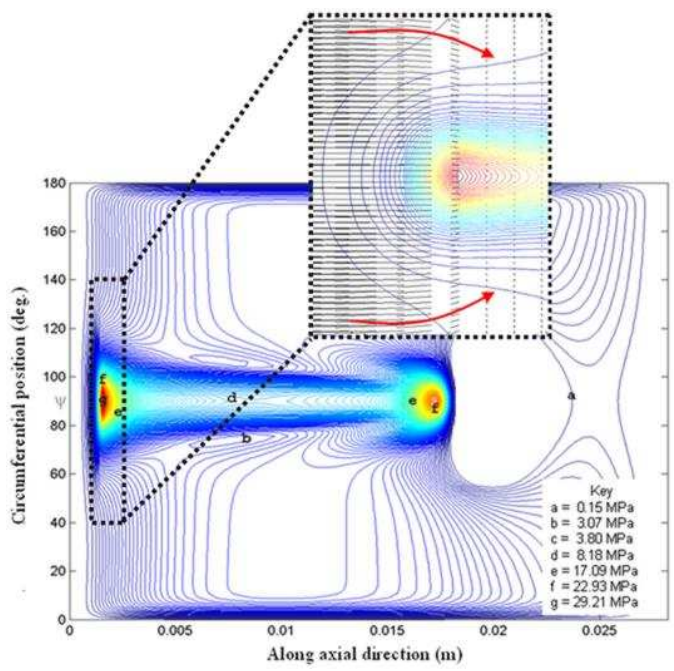

Figure 4. Piston skirt-cylinder liner isobaric contact pressure distribution.

The results in Figure 5 indicate that the same lasertextured pattern should be used in the engine tests shown in Figure 7, as discussed later. The method of analysis has been fully described by Balakrishnan et al. ${ }^{10}$ Analytical work by Spencer et al.12 with different cross-hatch honed liners also showed that the fabricated grooves themselves act as microwedges. 


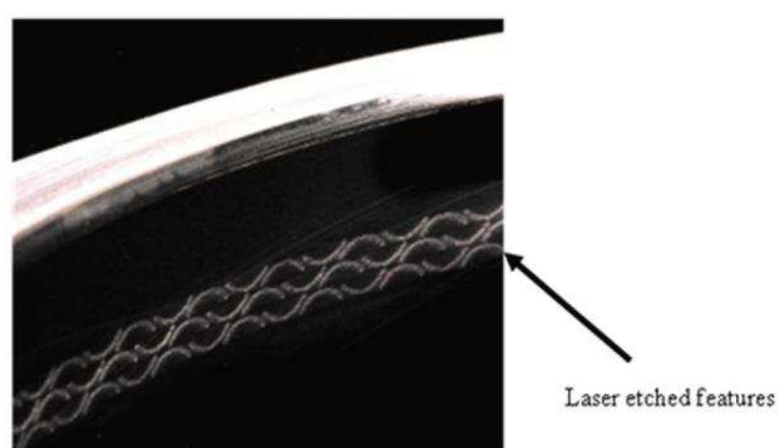

(a)

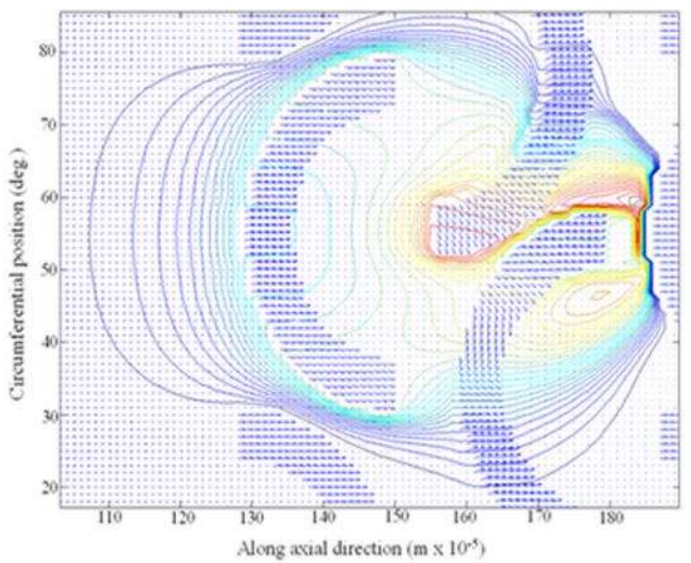

(b)

Figure 5. (a) Laser texturing on part L2017-L in the TDC region; (b) improved inlet flow pattern (i.e. the predicted inward inlet flow pattern with a reduced pressure spike) due to the laser-textured pattern at the TDC.

As already noted in the introduction, a series of analytical simulations by Rahmani et al.21 for the case of compression ring-cylinder bore contact has shown that lasertextured dimples of a conical geometry with a certain distribution, spacing and depth yield the highest load-bearing capacity, as well as reduced friction. These predictions generally agree with various experimental studies for different conjunctions.13, 14, 19, 20 Therefore, as an alternative, indentation texturing was applied in the TDC region to the liner variant $\mathrm{L} 2017-\mathrm{M}$, which otherwise is identical with the baseline liner. Figure 6(a) shows the indented region around the TDC, with the inset to the figure illustrating the employed pattern.

The indentation makes use of a standard Vickers pyramid diamond tool, which was held in a specially fabricated spring-loaded tool holder, presenting the working tip orthogonal to the surface of the liner. A Matsuura MC-800 VG2 machining centre with a four- or five-axis positioning unit was used to repeat the pattern circumferentially over the TDC region. A plan view of the imprint dimensions is shown in Figure 6(b).

It should be noted that the location of the lasertextured and indentation patterns on the described liners are such that the compression ring's working face is coincident with them during piston reversal at the TDC. Figure 7 shows the performance of the two textured liners against the baseline liner (the laser textured liner is that based on the analysis in Figure 5). Both textured liners show improved power compared with 
that of the baseline liner. The localised nature of texturing indicates that retention of a film of lubricant prior to and immediately after the TDC of the compression and power strokes reduced the dominance of solid boundary interactions. At lower engine speeds the laseretched texture performed the best, showing a power gain of up to $4 \%$ over that of the baseline liner. This is because the textured pattern encourages the flow of lubricant into the region of high contact pressures during the reversal (Figure 5). Note that the ablated pattern consists of a series of nested mirror arc grooves, which takes into account the instantaneous nature of contact inlet reversal. The Honda CRF-450R trials were validated using a high-performance Chevrolet Sprint Cup engine, showing increased output at rotational speeds below the maximum torque speed (not reported in detail here). As the rotational speed increased past this point, the performance was equivalent to those of the non-etched variants. With the indented pattern the microwedge effect is not as effective. The indented imprint pattern acts more like a reservoir of lubricant. Consequently, for increasing sliding velocity, while the laser-etched pattern directs the flow away, the same is not true of the indented pattern.

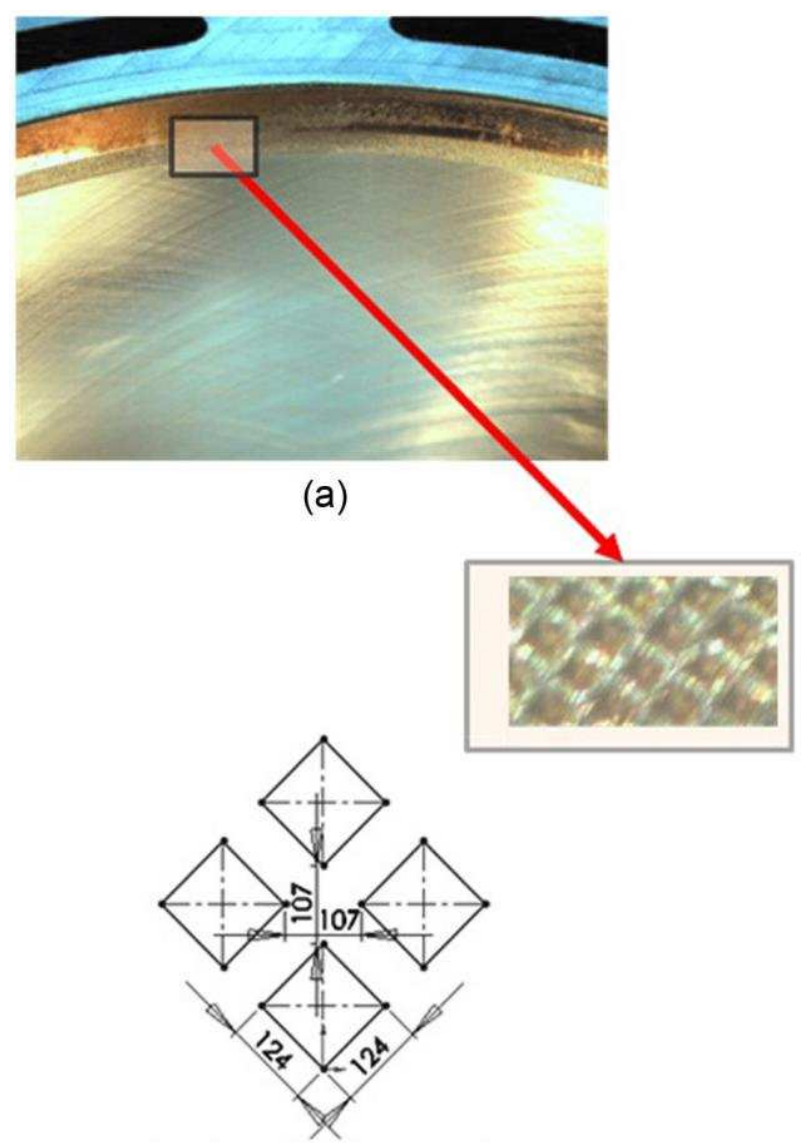

(b)

Figure 6. Liner with the indentation pattern at the TDC: (a) indented texturing at the TDC; (b) a plan view of the imprint dimensions in micrometres. 


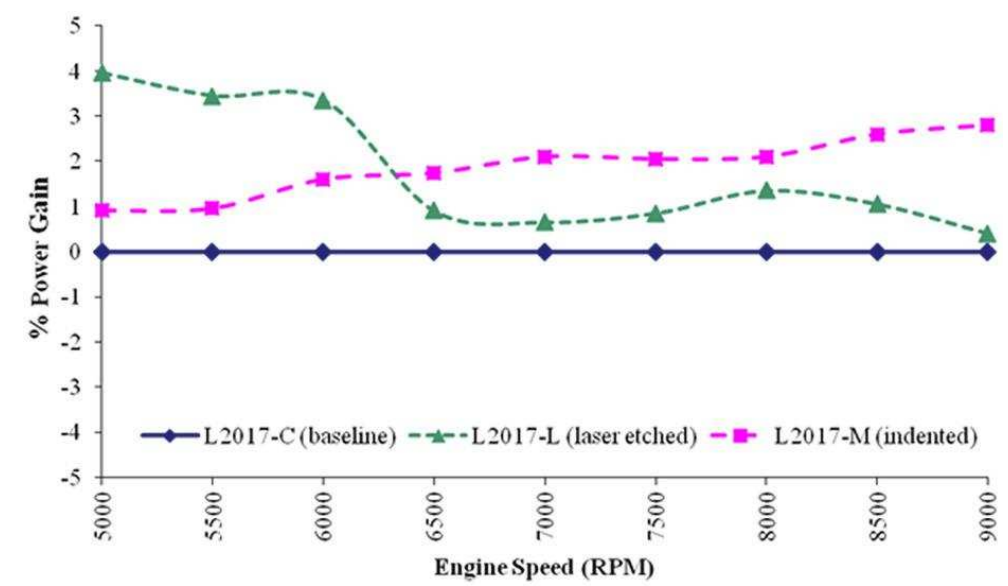

Figure 7. Performances of the TDC textured liners.

RPM: $r / \min$.

Hence, a larger volume of lubricant remains at the TDC in the latter case. One problem is that, with a sufficient supply of lubricant, the indented liner can retain too thick an oil film, which may breach the sealing function of the compression ring. In practice, the objective of reducing friction through laser texturing should be accompanied by consideration given to oil consumption, guarding against increased lubricant flow through the ring pack. In the reported tests the lubricant flow rate through the ring pack was not measured during testing as this was found to be difficult owing to the small sump and the short test duration. However, combustion products were monitored to ensure correct and repeatable conditions. Furthermore, no notable variation was observed in the air-to-fuel ratio nor in the hydrocarbon deposits in the ports and piping inspection carried out after all the tests. Wide-open throttle testing was seen as the only load case where oil burning could occur and, if oil burning did occur, it would lead to a power reduction (because the unavailability of oxygen results in an over-rich mixture). Continual monitoring of the air-to-fuel ratio ensured the integrity of the test data presented.

\section{Concluding remarks}

The regime of lubrication changes throughout the piston cycle. As a result, during the engine cycle, boundary interactions as well as viscous shear of the lubricant film contribute to the parasitic frictional losses. The contribution of boundary friction is dominant in piston reversals at the TDC and the BDC, and particularly in transition from the compression to the power stroke, as predicted and measured by many research workers. ${ }^{12,}$ 21, 32-36

To reduce the effect of boundary interactions, the lubricant-surface combination should be viewed as a system. From this viewpoint the adherence of lubricant to the bounding surfaces is a function of the lubricant molecular species, as well as the surface energy and topography. ${ }^{8}$ The paper has shown that some surface features may retain a volume of lubricant as shown by the predictions in Figure 5 and the 
enhanced output power of the textured liners in Figure 7. At the TDC and the BDC the presence of hard coatings resists wear.

Unfortunately, hard coatings are generally oleophobic to a certain degree. Thus, surface modification is beneficial at the TDC to create reservoirs of lubricant, which also encourage lubricant entrainment into the contact at low sliding speeds (the microwedge effect). Advice on the form or pattern, the distribution and the geometry of these features should be obtained through numerical analyses.

\section{Acknowledgement}

Thanks are due to Capricorn Automotive Ltd for technical support of this research.

\section{Funding}

This work was supported by the Engineering and Physical Sciences Research Council under an Encyclopaedic Program Grant (grant number) as well as by Capricorn Automotive Ltd (grant number).

\section{Declaration of conflict of interest}

The authors declare that there is no conflict of interest.

\section{References}

1. Rahnejat H. Multi-body dynamics: vehicles, machines and mechanisms. Bury St Edmunds: Professional Engineering Publishing, 1998. Warrendale, Pennsylvania: SAE International, 1998. ISBN 0768002699.

2. Andersson BS. Company's perspective in vehicle tribology - Volvo. In: Vehicle tribology, Tribology Series, Vol 18. Amsterdam: Elsevier, 1991, pp. 503-506.

3. Balakrishnan $\mathrm{S}$ and Rahnejat $\mathrm{H}$. Isothermal transient analysis of piston skirt-tocylinder wall contacts under combined axial, lateral and tilting motion. J Phys, Part D: Appl Phys 2005; 38(5): 787-799.

4. Gohar R and Rahneja H. Fundamentals of tribology. London: Imperial College Press, 2008.

5. Amontons $\mathrm{G}$. De la resistance causee dans les machines.

Me`m Acad R Sci, Paris 1699.

6. Coulomb CA. Theorie des machines simples, en ayant egard au frottement de leurs parties; et a la roideur des cordages. Me`m Acad R Sci, Paris 1781.

7. Erdemir A. Review of engineered tribological interfaces for improved boundary lubrication. Tribol Int 2005; 38(3): 249-256.

8. Chong WWF, Teodorescu M and Rahnejat $\mathrm{H}$. Nanoscale elastoplastic adhesion of wet asperities. Proc IMechE Part J: J Engineering Tribology 2013; 227(9): 996-1010.

9. Balakrishnan S, Howell-Smith S, Rahnejat H and Dowson D. Investigation of reciprocating conformal contact of piston skirt and ring-pack to cylinder liner under transient condition. In: 30th Leeds-Lyon symposium on tribology, Transient 
processes in tribology, Tribology Series, Vol 43, Lyon, France, 2-8 September 2003, pp. 265-273. Amsterdam: Elsevier.

10. Balakrishnan S, Howell-Smith $S$ and Rahnejat H. Investigation of reciprocating conformal contact of piston skirtto-surface modified cylinder liner in high performance engines. Proc IMechE Part C: J Mechanical Enginering Science 2005; 219: 12351247.

11. Michail SK and Barber GC. The effects of roughness on piston ring lubrication Part II: the relationship between cylinder wall surface topography and oil film thickness. STLE Tribol Trans 1995; 38(1): 173-177.

12. Spencer A, Almqvist A and Larsson R. A numerical model to investigate the effect of honing angle on the hydrodynamic lubrication between a combustion engine piston ring and cylinder liner. Proc IMechE Part J: J Engineering Tribology 2011; 225(7): 683-689.

13. Ryk G, Kligerman $Y$ and Etsion I. Experimental investigation of laser surface texturing for reciprocating automotive components. STLE Tribol Trans 2002; 45: 444- 449.

14. Kovalchenko A, Ajayi O, Erdemir A, et al. The effect of laser surface texturing on transitions in lubrication regimes during unidirectional sliding contact. Tribol Int 2005: 38: 219-225.

15. Rahnejat $\mathrm{H}$, Balakrishnan S, King PD and Howell-Smith S. In-cylinder friction reduction using a surface finish optimization technique. Proc IMechE Part D: J Automobile Engineering 2006; 220(9): 1309-1318.

16. Etsion I and Sher E. Improving efficiency with laser surface textured piston rings. Tribol Int 2009; 42(4): 542-547.

17. Dumitru G, Romano V, Weber HP, et al. Laser microstructuring of steel surfaces for tribological applications. Appl Phys A: Mater Sci Processing 2000; 70(4): 485487.

18. Andersson $P$, Koskinen J, Varjus $S$, et al. Microlubrication effect by lasertextured steel surfaces. Wear 2007; 262: 369-379.

19. Morris N, Rahmani $R$ and Rahnejat $\mathrm{H}$. Tribology of partial pad journal bearings with textured surfaces. In: 3rd European conference on tribology, Vienna, Austria, June7-9, 2011, pp. 645-650. Vienna: Osterreichische Tribologische Gesellschaft.

20. Etsion I. Surface texturing for in-cylinder friction reduction. In: Rahnejat $\mathrm{H}$ (ed) Tribology and dynamics of engine and powertrain. Cambridge: Woodhead Publishing, 2010, pp. 458-469.

21. Rahmani R, Shirvani $A$ and Shirvani H. Optimised textured surfaces with application in piston ring/cylinder liner contact. In: Rahnejat $\mathrm{H}$ (ed) Tribology and dynamics of engine and powertrain. Cambridge: Woodhead Publishing, 2010, pp. 470-517. 
22. Funatani K, Kurosawa K, Fabiyi PA and Puz MF.

Improved engine performance via use of nickel ceramic composite coatings. SAE paper 940852, 1994.

23. Dearnley PA, Gummersbach J, Weiss $\mathrm{H}$, et al. The sliding wear resistance and frictional characteristics of surface modified aluminium alloys under extreme pressures. Wear 1999; 225-229: 127-134.

24. Totten G and MacKenzie D. Handbook of aluminum Vol 2 - alloy production and materials manufacture. New York: Marcel Dekker, 2003.

25. Donnet $C$ and Erdemir A. Solid lubricant coatings: recent developments and future trends. Tribol Lett 2004; 17(3): 389-397.

26. Mistry KK. Lubricated DLC - truly diamond-like-performance. In: Mission of tribology research 17, London, UK, 3 December 2008. London: Institution of Mechanical Engineers.

27. Perera MSM, Theodossiades S and Rahnejat H. Elastomulti-body dynamics of internal combustion engines with tribological conjunctions. Proc IMechE Part K: J Multibody Dynamics 2010; 224(3): 261-277.

28. Burbidge D, Howell-Smith S and Teodorescu M. Fractal characterisation of inhomogeneous rough surfaces In: ASME 2011 international design engineering technical conferences and computers and information in engineering conference, Washington, DC, USA, 28-31August 2011, Vol 7, paper DETC2011-47856, pp. 401404. New York: ASME.

29. Gore M, Styles G, King PD and Rahnejat H. Wear characteristics of advanced honed and cross-hatched coated cylinder liners. In: 2011 STLE annual meeting and exhibition, ASME/STLE international joint tribology conference, Atlanta, Georgia, USA, 15-19 May 2011, pp. 214-217. Park Ridge, Illinois: STLE.

30. Theaker M, Rahmani R and Rahnejat $\mathrm{H}$. Prediction of ring-bore conformance and contact condition and experimental validation. In: ASME 2012 Internal Combustion Engine Division spring technical conference, Turin, Italy, 6-9 May 2012, paper ICES2012-81021, pp. 885-893. New York: ASME.

31. Furuhama S and Sasaki S. New device for the measurement of piston frictional forces in small engines. SAE paper 831284, 1983.

32. Gore M, Howell-Smith S, King PD and Rahnejat H. Measurement of in-cylinder friction using the floating liner principle. In: ASME 2012 Internal Combustion Engine Division spring technical conference, Turin, Italy, 6-9 May 2012, paper ICES201281028, pp. 901-906. New York: ASME.

33. Ma MT, Smith EH and Sherrington I. Analysis of lubrication and friction for a complete piston-ringpack with an improved oil availability model, Part 2:

circumferentially variable film. Proc IMechE Part J: J Engineering Tribology 1997;

211: 17-27. 
34. Akalin $\mathrm{O}$ and Newaz GM. Piston ring cylinder bore friction modelling in mixed lubrication regime, Part I: analytical results. Trans ASME, J Tribol 2001; 123: $211-$ 218.

35. Mishra $\mathrm{P}$, Rahnejat $\mathrm{H}$ and King PD. Tribology of the ring-bore conjunction subject to a mixed regime of lubrication. Proc IMechE Part C: J Mechanical Engineering Science 2009; 223: 987-998.

36. Jaffar MJ. Asymptotic behaviour of thin elastic layers bonded and unbonded to a rigid foundation. Int J Mech Sci 1989; 31: 229-235.

37. Naghieh GR, Rahnejat $\mathrm{H}$ and Jin ZM. Characteristics of frictionless contact of bonded elastic and viscoelastic layered solids. Wear 1999; 232: 243-249.

38. Teodorescu M, Rahnejat H, Gohar R and Dowson D. Harmonic decomposition analysis of contact mechanics of bonded layered elastic solids. Appl Math Modelling 2009; 33(1): 467-485.

39. Teodorescu $\mathrm{M}$ and Rahnejat $\mathrm{H}$. Mathematical modelling of layered contact mechanics of cam-tappet conjunction. Appl Math Modelling 2007; 31(11): 26102627.

40. Goltsberg R, Etsion I and Davidi G. The onset of plastic yielding in a coated sphere compressed by a flat rigid. Wear 2011; 271: 2968-2977.

41. Cai TX, Zhang PY and Diao DF. Evolution of maximum contact stresses in amorphous carbon coated silicon during sliding wear against Si3N4 ball. Trans ASME, J Tribol 2013; 135(2): 021401-1-021401-10.

42. McClure F. Numerical modeling of piston secondary motion and skirt lubrication in internal combustion engines. Cambridge, Massachusetts: MIT Press, 2007.

43. Littlefair B, Howell-Smith S, Theodossiades S, et al. Tribology of piston skirt conjunction. In: 3rd European conference on tribology, Vienna, Austria, June7-9, 2011, pp. 739-743. Vienna: Osterreichische Tribologische Gesellschaft.

44. Ryk $G$ and Etsion I. Testing piston rings in partial laser surface texturing for friction reduction. Wear 2006; 261(7-8): 792-796.

45. Ryk G, Kligerman $Y$ and Etsion I. Experimental investigation of partial laser surface texturing for piston-ring friction reduction. Tribol Trans 2005; 48(4): 583-588.

46. Rahmani R, Theodossiades $\mathrm{S}$, Rahnejat $\mathrm{H}$ and Fitzsimons $\mathrm{B}$. Transient elastohydrodynamic lubrication of rough new or worn piston compression ring conjunction with an out-of-round cylinder bore. Proc IMechE Part J: J Engineering Tribology, 2012; 226(4): 284-305. 
